Earth Interactions - Volume 16 (2012) - Paper No. 4 • Page 1

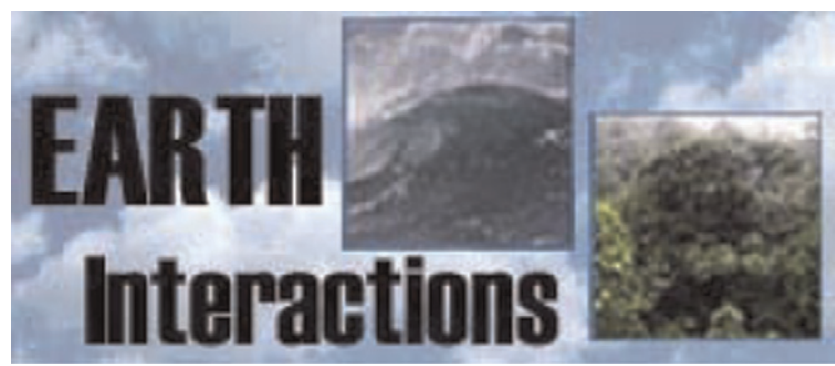

Copyright $\odot$ 2012, Paper 16-004; 10507 words, 5 Figures, 0 Animations, 5 Tables. http://EarthInteractions.org

\title{
Exploring Surface Biophysical- Climate Sensitivity to Tropical Deforestation Rates Using a GCM: A Feasibility Study*
}

\section{Kendra Gotangco Castillo ${ }^{+}$}

Department of Earth and Atmospheric Sciences, and Purdue Climate Change Research Center, Purdue University, West Lafayette, Indiana

\section{Kevin Robert Gurney}

Department of Earth and Atmospheric Sciences, and Purdue Climate Change Research Center, Purdue University, West Lafayette, Indiana, and School of Life Sciences, Arizona State University, Tempe, Arizona

Received 7 November 2010; accepted 10 September 2011

\begin{abstract}
Deforestation perturbs both biophysical and carbon feedbacks on climate. However, biophysical feedbacks operate at temporally immediate and spatially focused scales and thus may be sensitive to the rate of deforestation rather than just to total forest-cover loss. Explored here is a method for simulating annual tropical deforestation in the fully coupled Community Climate System Model, version 3.0 (CCSM3) with the Dynamic Global Vegetation Model (DGVM) for testing biosphere climate sensitivity to "preservation pathways." Two deforestation curves were simulated-a $10 \%$ deforestation curve with a $10 \%$ preservation target (DFC10-PT10) versus a $1 \%$ deforestation
\end{abstract}

* Supplemental information related to this paper is available at the Journals Online Web site: http://dx.doi.org/10.1175/2011EI390.s1.rar.

${ }^{+}$Corresponding author address: C. Kendra Gotangco Castillo, Manila Observatory, Ateneo de Manila University Campus, Loyola Heights, Quezon City 1120, Philippines.

E-mail address: kgotangco@observatory.ph 
Earth Interactions - Volume 16 (2012) • Paper No. 4 • Page 2

curve with a $10 \%$ preservation target (DFC1-PT10). During active deforestation, albedo, net radiation, latent heat flux, and climate variables were compared for time dependence and sensitivity to tropical tree cover across the tropical band and the Amazon basin, central African, and Southeast Asian regions. The results demonstrated the feasibility of modeling incremental deforestation and detecting both transient and long-term impacts, although a warm/dry bias in CCSM3-DGVM and the absence of carbon feedbacks preclude definitive conclusions on the magnitude of sensitivities. The deforestation rates produced characteristic trends in biophysical variables with DFC10-PT10 resulting in rapid increase/decrease during the initial 10-30 years before leveling off, whereas DFC1-PT10 exhibits gradual changes. The rate had little effect on biophysical and climate sensitivities when averaged over tropical land but produced significant differences at a regional level. Over the long term, the rates produced dissimilar vegetation distributions, despite having the same preservation target in both cases. Overall, these results indicate that the question of rates is one worth further analysis.

KEYWORDS: Tropical deforestation; Preservation pathways; Dynamic vegetation; Biophysical feedbacks; Climate feedbacks

\section{Introduction}

Deforestation and forest degradation continue to be a significant contributors to total anthropogenic carbon dioxide $\left(\mathrm{CO}_{2}\right)$ emissions, with Intergovernmental Panel on Climate Change (IPCC) estimates at 20\% between 1989 and 1998 (Robledo and Blaser 2008; Nabuurs et al. 2007), updated to $12 \%$ by Van der Werf et al. (Van der Werf et al. 2009). Tropical deforestation, in particular, is projected to remain high, particularly in Africa and South America, until 2050 (Nabuurs et al. 2007), thus driving biosphere-atmosphere dynamics (Barker et al. 2007). International negotiations for a post-2012 climate policy infrastructure are considering a wider role for the agriculture, forestry, and other land-use (AFOLU) sector in climate change mitigation (Hassan et al. 2005). The 2010 Cancun agreements specifically call for the establishment of enhanced mechanisms for Reducing Emissions from Deforestation and Forest Degradation (REDD).

REDD has driven the need for more research to improve carbon accounting methodologies. Much effort is being directed toward resolving technical difficulties in determining baseline scenarios and accurately accounting for changes in carbon stocks. To solve part of the policy design problem, Gurney and Raymond (Gurney and Raymond 2008) propose a "preservation pathway" approach, which allocates credits based on the relative decline in deforestation rates between commitment periods. By crediting countries that show decreasing deforestation, a forest preservation target can be attained as countries approach near-zero net tree removal. Although this approach could potentially streamline the carbon accounting process, it raises an important question: is the pathway itself as important as the preservation target?

Land-use changes can perturb climate through avenues other than the carbon cycle, avenues that may be influenced by the pathway of change. Biosphereatmosphere dynamics are as profoundly affected by biophysical factors such as albedo, the surface radiation budget, surface roughness, sensible versus latent heat fluxes, and the hydrological cycle. That biophysics can play a role comparable to 
Earth Interactions • Volume 16 (2012) • Paper No. 4 • Page 3

carbon in influencing regional and global climate has been consistently supported by studies to date (e.g., Davin and de Noblet-Ducoudré 2009; Bonan 2008; Canadell and Raupach 2008; Chapin et al. 2008; Jackson et al. 2008; Schurgers et al. 2008; Feddema et al. 2005; Gibbard et al. 2005; Sitch et al. 2005; Marland et al. 2003; Pielke et al. 2002; Govindasamy et al. 2001; Betts 2000; Brovkin et al. 1999). The extent to which certain factors dominate has been found to depend greatly on location. Climate response in the boreal regions is largely influenced by radiative forcing due to changes in albedo. Deforestation increases albedo, decreases solar radiation absorbed at the surface, and reinforces the snow/ice albedo feedback, leading to net global cooling (Bala et al. 2007; Claussen 2001; Betts 2000; Brovkin et al. 1999; Bonan et al. 1992). Simulations have similarly shown that, in the midlatitudes, conversion of vegetation to grasslands can lead to cooling, whereas replacement by tree cover or biomass plantations can lead to warming (Schaeffer et al. 2006; Gibbard et al. 2005; Govindasamy et al. 2001). The magnitude of this warming can be comparable to the cooling caused by forest carbon uptake and storage (Gibbard et al. 2005).

In contrast, deforestation in the tropics and subtropics results in increased surface temperatures. The climate response is dominated by carbon release, a decrease in evapotranspiration, and a subsequent decrease in cloud formation (Bala et al. 2007; Gibbard et al. 2005; Snyder et al. 2004; Claussen et al. 2001; Zhang et al. 2001; Henderson-Sellers et al. 1993). Eight trillion tons of water evaporate from the Amazon alone (Nepstad et al. 2008). Thus, even small-scale deforestation can impact local clouds and precipitation through changes in mesoscale circulation (Bonan 2008).

Although deforestation is a process that perturbs both biophysical and carbon feedbacks, it has typically been implemented in global or large-scale modeling studies as a mass instantaneous replacement of trees (e.g., Davin and de NobletDucoudré 2009; Bala et al. 2007; Findell et al. 2006; Avissar and Werth 2005; Gibbard et al. 2005; Snyder et al. 2004). This method is appropriate for investigating equilibrium impacts but gives little information about transient climatic changes that may occur as the system adjusts. Biophysical and biogeochemical variables work at different temporal and spatial scales. Biophysical feedbacks are stronger at regional scales and more immediate in response (i.e., change in albedo is instantaneous), whereas carbon feedbacks are global and lagged in time because of dissolution and circulation of $\mathrm{CO}_{2}$ in the ocean (resulting in the twentiethcentury "climate change commitment"). Given the more proximate response of biophysical feedbacks, the resulting climate may be sensitive to how deforestation actually proceeds.

Poulter et al. (Poulter et al. 2009) and Gumpenberger et al. (Gumpenberger et al. 2010) calculate deforestation in the tropics on an annual time step, but with the Lund-Potsdam-Jena managed Land (LPJmL) Dynamic Global Vegetation Model (DGVM) in the offline mode [driven by Special Report on Emission Scenarios (SRES) A2 projections] and with the focus on impacts on carbon dynamics. Work by Lawrence and Chase (Lawrence and Chase 2010) investigates the overall climate feedbacks of global transient land-use change using the fully coupled Community Climate System Model (CCSM) but, although the simulated annual land-cover changes are broader and historically more accurate, they are in prestaged input rather than being fully interactive with climate. Hence, there remain critical scientific and 
policy questions regarding the space and time evolution of deforestation feedbacks on climate.

This preliminary work therefore attempts, first, to experiment with implementing incremental deforestation in a global climate model (GCM); second, to determine if this annual deforestation results in a corresponding time dependence within biophysical-climate impacts of deforestation; and, third, to explore methods for expressing these potential biophysical-climate sensitivities to the transient deforestation. This work tests if the rates of deforestation indeed affect terrestrial biophysical-climate feedbacks and at what spatial scale can these impacts be detected, during the period of active deforestation using the GCM. By "active deforestation period," we refer to the transient period during which annual deforestation is applied. We also comment on the "postdeforestation" period, which follows after the preservation target is reached and the forced removal of trees ceases (although it is recognized that, in reality, given socioeconomic considerations, it is not likely that human-induced deforestation will cease completely tropics-wide, though the net deforestation may be zero if reforestation/afforestation is applied).

Whereas previous work has focused on the impacts of particular land-cover state, this research focuses on the sensitivity of the Earth system to the speed by which that end state is achieved, that is, the sensitivity to the rate of change in addition to the final change itself. The purpose of this work is not to project climatic changes but to demonstrate whether it is feasible to simulate and detect the impacts of these rates given an available GCM and whether the question of rates is one of importance and worth further analysis. Note that this work focuses on the biophysical-climate feedbacks because biogeochemistry is not fully coupled in the GCM. Although atmospheric $\mathrm{CO}_{2}$ concentrations are an input to net primary productivity in the DGVM, the net ecosystem exchange does not affect atmospheric concentrations.

Section 2 provides the methods by which deforestation is implemented within the model code and the simulation descriptions. Section 3 presents the results in terms of vegetation change, biophysical feedbacks, and climate impacts during and after deforestation. Sections 4 and 5 discuss the implications on science and policy and outline recommendations for future research.

\section{Methods}

The GCM used here is the CCSM, version 3 (CCSM3) (Collins et al. 2006), which consists of atmosphere, land, ocean, and sea ice components linked through a coupler. The land component, the Community Land Model (CLM), includes the DGVM (Bonan and Levis 2006; Levis et al. 2004). Experiments described here are run with CCSM3 in the standard fully coupled mode, with all the components, including the DGVM, active. The parameterizations of this DGVM are based largely on the Lund-Potsdam-Jena (LPJ) model, which is documented and evaluated by Sitch et al. (Sitch et al. 2003).

Deforestation was introduced to the DGVM establishment and survival module as a population "thinning" of each tree plant functional type (PFT) resulting in a decrease of tree foliar projective cover. A fixed percentage of the population density (in this case, $10 \%$ versus $1 \%$ ) was removed each year and transferred to the appropriate above- and below-ground litter pools, creating a "deforestation curve" (DFC). Establishment of new tree saplings was controlled so that the space vacated 
Earth Interactions • Volume 16 (2012) • Paper No. 4 • Page 5
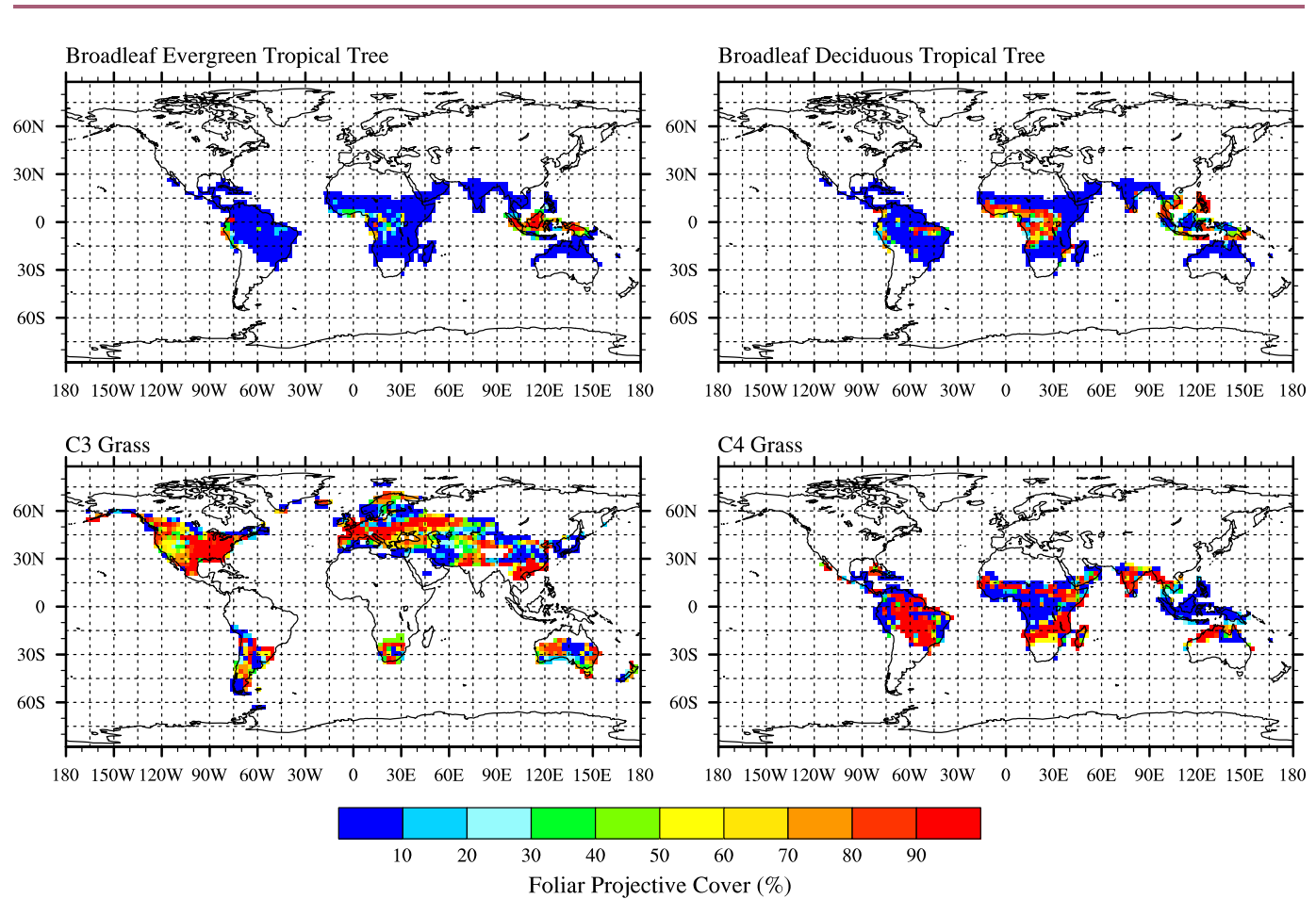

Figure 1. Foliar projective cover of tropical trees and grasses at the end of the 100 -yr fully coupled spinup and prior to the deforestation branch cases. Shown are the (top left) broadleaf evergreen tropical tree, (top right) broadleaf deciduous tropical tree, (bottom left) C3 grass, and (bottom right) $\mathrm{C} 4$ grass.

by the trees could be colonized by grasses (or remain bare depending on climatic conditions). This deforestation algorithm was implemented throughout the entire tropical band $\left(30^{\circ} \mathrm{S}-30^{\circ} \mathrm{N}\right)$. A forest preservation target of $10 \%$ was imposed on a per-tree PFT basis; that is, deforestation of a particular tree did not occur if the foliar projective cover of this type was already less than $10 \%$ of the grid cell's total vegetated area.

The preservation target acts as a threshold beyond which human-induced deforestation is deactivated, rather than as a forced end state. The $10 \%$ target refers to the fraction of the gridcell area covered by the PFT (and there are more than one PFT within a grid cell's vegetated area) rather than its remaining population. It ensures that individuals of each naturally occurring PFT within a grid cell remain. Thus, under this scheme, grid cells are deforested at the same yearly rate relative to their current population but are not deforested equally in terms of number of individual removed and total forest cover cleared because they have different initial conditions (see Figure 1). For example, broadleaf evergreen tree cover, which occupies $90 \%$ of the vegetated area in Southeast Asia, will lose individuals until that PFT covers only $10 \%$ of the vegetated area. In the Amazon basin, evergreens are simulated to cover $20 \%$ and will also lose individuals until the $10 \%$ threshold. In the first instance, however, the evergreen cover is reduced by $80 \%$, whereas, in the latter, it is reduced by $10 \%$. 
This scheme represents the most straightforward means of implementing timedependent deforestation combined with preservation targets within the CLM3DGVM framework. The human component remains prescribed but only to the extent of dictating the deforestation rate and controlling of tropical tree regrowth. This aspect cannot be made prognostic in the absence of a decision-making model to simulate human land-use decisions in response to climate. However, the process and rate of establishment remains prognostic for grasses everywhere and trees outside of the tropical band. More importantly, vegetation dynamics are fully interactive with climate in all other aspects, that is, the survival of all PFTs under given climatic conditions, fire and gap mortality, competition for resources, photosynthesis and growth, and seasonal phenology. Thus, given the suppression of establishment of tropical tree types, even when the forced deforestation ceases, the tree PFT cover in the tropics will gradually decrease from $10 \%$ as natural causes of mortality take effect.

An offline 500-yr surface spinup was performed using only CLM3-DGVM. The results were then used as initial conditions for a 100-yr fully coupled spinup using CCSM3. Three branch runs were then conducted diverging from year 101 of the spinup: 1) a control run at modern-day $\mathrm{CO}_{2}$ levels (control); 2) a deforestation run with an annual forest removal rate of $10 \%$ of the population density and a preservation target of 10\% (DFC10-PT10); 3) a deforestation run with an annual forest removal rate of $1 \%$ of the population density and a preservation target of $10 \%$ (DFC1-PT10). These scenarios were run at the T42 resolution (64 latitudes by 128 longitudes, approximately $2.8^{\circ}$ by $2.8^{\circ}$ ). $\mathrm{CO}_{2}$ levels were set at a modern-day value of 355 ppmv.

The choice of test rates that differ by an order of magnitude (10\% versus $1 \%$ ) in this sensitivity analysis was for the purpose of generating distinguishable signals in the biophysical-climate feedbacks. The $10 \%$ case represents an extreme scenario of which very few countries reach. For example, according to the Global Forest Resources Assessment (FAO 2010), the country Comoros experienced the largest annual loss of forest area at $9.7 \%$ from 2005 to 2010 . On the other hand, the $1 \%$ rate is within the range of many countries and regions. From 2005 to 2010, the average loss of forest area in Central and South America were $1.2 \%$ and $0.41 \%$, respectively. Rates in Africa and Asia are lower at $0.46 \%$ in western and central Africa and $0.33 \%$ in South and Southeast Asia. Having such a gap between the two rates reduced the probability that the differences between the two forcings were merely noise.

Analysis includes characterization of both active and postdeforestation biophysical and climate states averaged over the tropics. The first 50 years of the branch simulations - a period that spans short-, middle-, and long-term decision making for most policy issues-were designated as the active deforestation period. Selected variables were reported primarily in terms of both trends in time and trends against total tropical PFT foliar projective cover during this time span. The Pearson correlation coefficients of all trends during the active deforestation period were calculated, and statistical significance was set at a $95 \%$ level.

The trends in time were determined by applying linear regression to the difference between the deforestation scenarios and the control, labeled as $\triangle \mathrm{DFC} 10$ for the change in the DFC10-PT10 and as $\triangle \mathrm{DFC} 1$ for the change in the DFC1-PT10 case relative to the control. This differencing was performed to remove any background 
Earth Interactions - Volume 16 (2012) • Paper No. 4 • Page 7

trends. The time dependence of the biophysical and climate response was represented by the slopes of each variable in the $\triangle \mathrm{DFC} 10$ and $\triangle \mathrm{DFC} 1$ cases.

However, because the tree population to be deforested was determined relative to existing populations, areas with more trees lost a greater number of individuals while areas already near the preservation target will experience minimal deforestation. The latter case appeared as a weaker trend in time though it did not necessarily imply weaker sensitivity. Differences in the tree cover lost each year contributed to the differences in annual trends; thus, the perturbations applied yearly were not equal across the different regions. To address this, the forcing was normalized by comparing biophysical and climate variables against total tropical tree (deciduous and evergreen) foliar projective cover. The sensitivity to forest cover of each variable was then defined as the slope of the plot of that variable against the total tropical PFT foliar projective cover. Determining the change in biophysical and climate variables per unit area of tropical tree cover made it possible to directly compare regional responses to deforestation rates despite differences in forest-cover spinup.

Because part of the objective was to determine if the pathway (i.e., a higher rate of deforestation over a shorter time frame versus a gradual rate over a longer time frame) would lead to different results despite having the same preservation target built into both scenarios, analysis of postdeforestation biophysical and climatic means was required. Equilibrium means were calculated over tropical land grid cells and weighted by the gridcell area, the fraction actually comprised of land (i.e., excluding lakes and seas, if coastal), and the fraction of land occupied by the vegetation. A $t$ test was applied, likewise using a 95\% significance level. For both active and postdeforestation periods, the analysis over tropical land was supplemented by analysis over major tropical forests in the Amazon basin $\left(10^{\circ} \mathrm{S}-0^{\circ}\right.$, $\left.70^{\circ}-50^{\circ} \mathrm{W}\right)$, central Africa $\left(5^{\circ} \mathrm{S}-5^{\circ} \mathrm{N}, 10^{\circ}-30^{\circ} \mathrm{E}\right)$, and Southeast Asia $\left(10^{\circ} \mathrm{S}-10^{\circ} \mathrm{N}\right.$, $\left.90^{\circ}-150^{\circ} \mathrm{E}\right)$.

\section{Results}

\subsection{Land-cover change}

The results presented here compare multidecadal biophysical and climate impacts of the deforestation rate simulations during the active deforestation period. This covers the first 50 years of the branch simulations (simulation years 101-150), during which forest populations are decreased incrementally until the minimum PFT cover is reached. Figures 1-3 show the spatial distribution of the foliar projective cover of the tropical tree and grass PFTs after the spinup stage (prior to the deforestation branch simulations) and after 50 years of the branch simulation in the DFC10-PT10 and DFC1-PT10 cases. Initially, broadleaf evergreen and deciduous tropical trees are the dominant tree types, although the evergreens are underestimated and grasses are overestimated. The model contains a warm, dry bias over the Amazon basin (Lawrence et al. 2007; Bonan and Levis 2006), causing it to be the least forested of the three major tropical forest regions, having many grid cells with evergreen cover already near or at the preservation target. Because of this, the impacts of deforestation are not as apparent here compared to denser forests in central Africa and Southeast Asia (where there is actually a wet bias when CLM3 is coupled to CAM3; Bonan and Levis 2006). For this reason, the following discussion 
Earth Interactions - Volume 16 (2012) • Paper No. 4 • Page 8
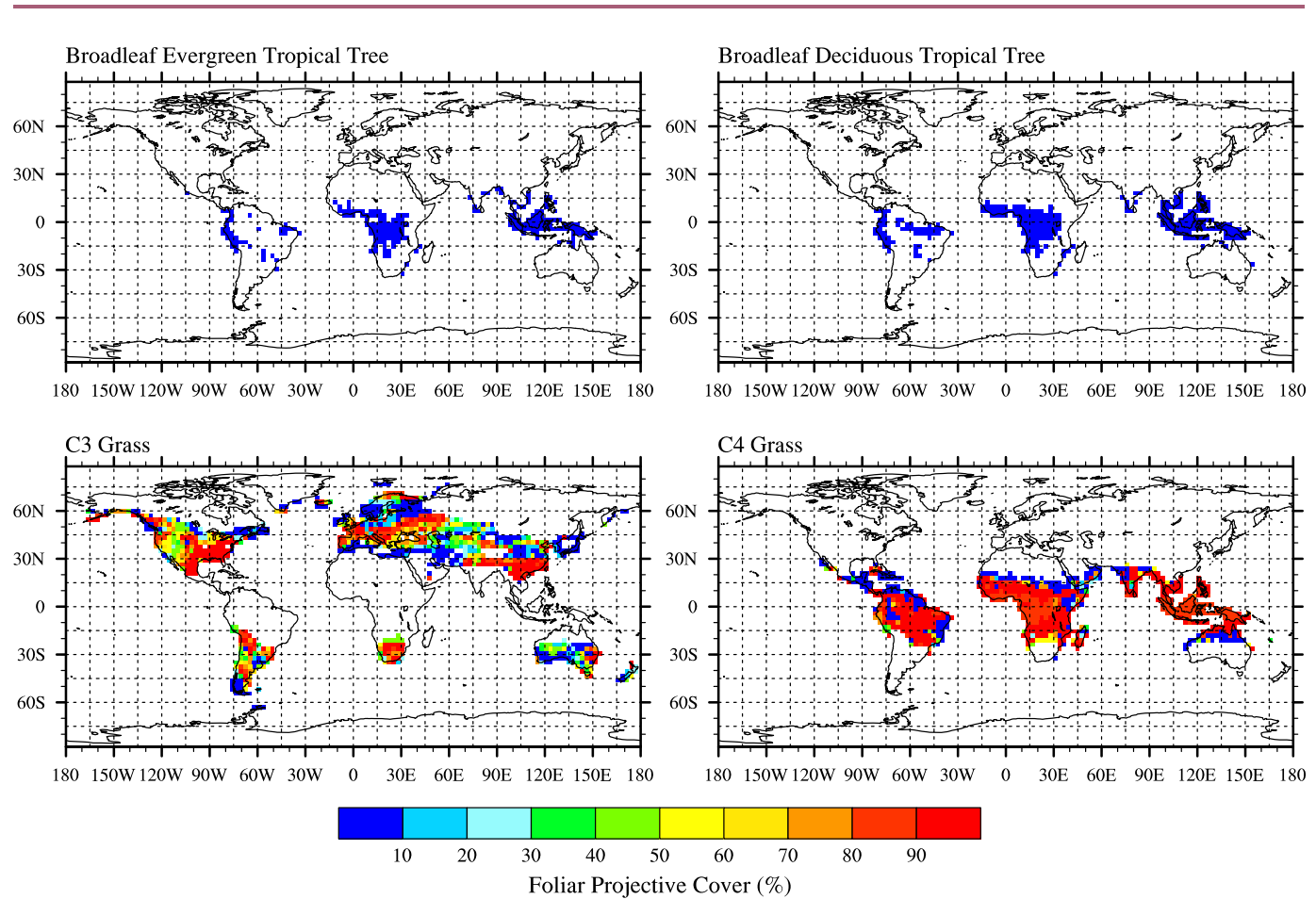

Figure 2. Foliar projective cover of tropical trees and grasses at the end of 50 years of the DFC10-PT10 case. Shown are the (top left) broadleaf evergreen tropical tree, (top right) broadleaf deciduous tropical tree, (bottom left) C3 grass, and (bottom right) C4 grass.

of trends in time (section 3.2) focuses on central Africa and Southeast Asia, whereas the discussion of trends normalized on a per-unit area basis (section 3.3) includes all three regions. Furthermore, the discussion focuses on relevant insights on the feasibility of modeling deforestation rates rather than absolute quantification of sensitivities.

As deforestation progresses, the dominant PFT cover transitions to grasses, particularly $\mathrm{C} 4$ grasses. After 50 years of the branch run, the tropical trees of the DFC10-PT10 case are already within $10 \%$ or below of their potential foliar cover, whereas grasses are at $80 \%-100 \%$ of their foliar cover, indicating that deforestation has ceased. Thus, the postdeforestation period for the DFC10-PT10 is defined as the second 50-yr period (branch run years 51-100; simulation years 151-200). The DFC1-PT10 case, by contrast, still contains considerable deciduous tree cover in central Africa (up to 70\%) and evergreen cover in Southeast Asia (up to 50\%), requiring a longer simulation in order to compare postdeforestation climate. The evergreens in DFC1-PT10, having less cover to begin with, reach the preservation target shortly after the first 100 years of the branch run. Deciduous trees still cover $10 \%-20 \%$ of the vegetated area of grid cells in central Africa and Southeast Asia after 200 years of the branch run. Hence, the branch years 251-300 (351-400 of the simulation) are designated as the postdeforestation period for the DFC1-PT10 case. However, because an additional 150 years of simulation were required after the 
Earth Interactions - Volume 16 (2012) • Paper No. 4 • Page 9
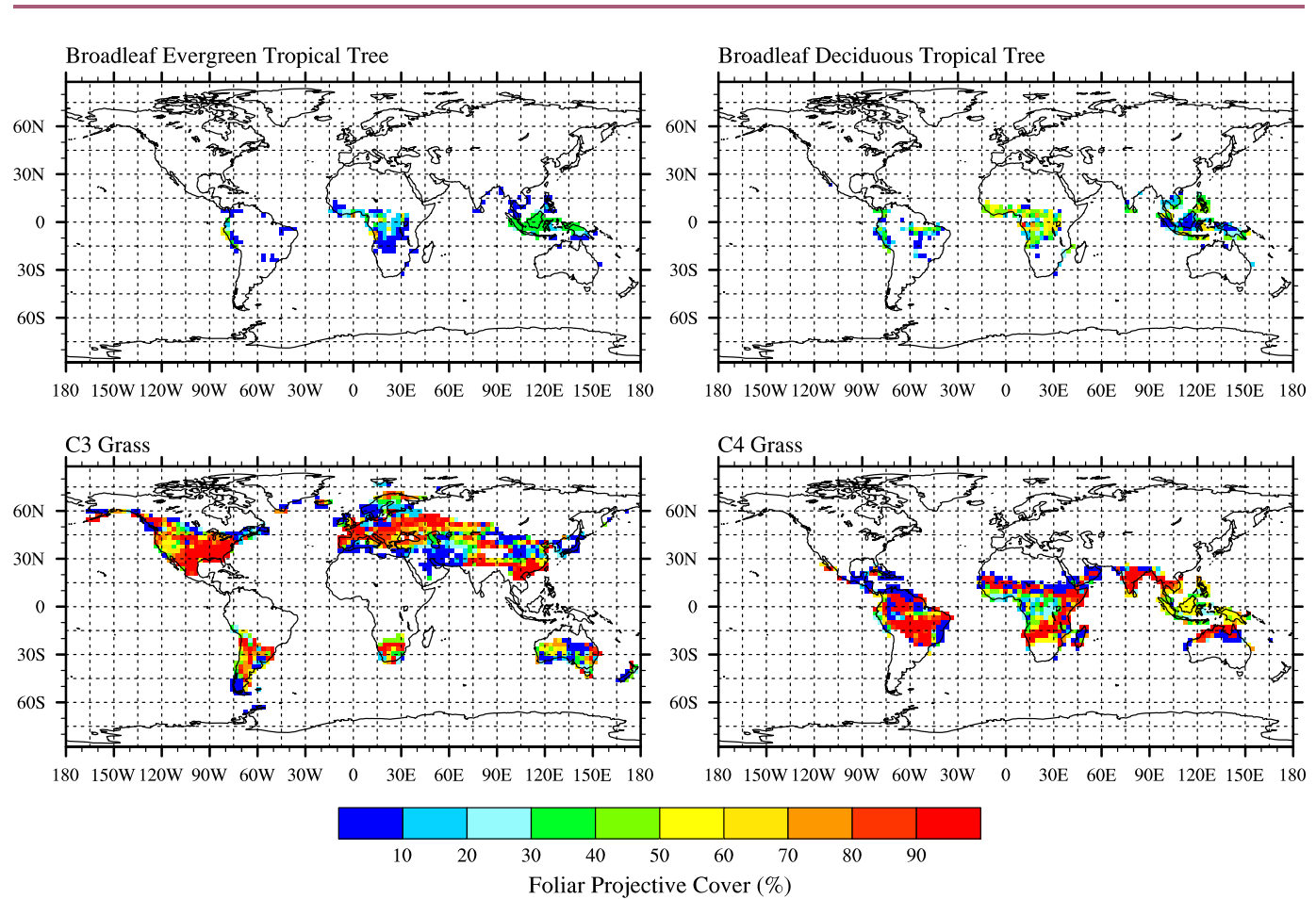

Figure 3. Foliar projective cover of tropical trees and grasses at the end of 50 years of the DFC1-PT10 case. Shown are the (top left) broadleaf evergreen tropical tree, (top right) broadleaf deciduous tropical tree, (bottom left) C3 grass, and (bottom right) $\mathrm{C} 4$ grass.

evergreens reached the preservation target in order to attain the required decrease in deciduous tree cover, the remaining evergreen coverage is less than in the DFC10-PT10 case because of natural causes of mortality operating alongside the forced deforestation (Figure 4).

The vegetation, biophysics, and climate respond and interact in accordance with the applied perturbation, creating different pathways toward new PFT distributions. Thus, despite having the same preservation target, it becomes impossible for the mean tree cover to be exactly the same in the postdeforestation periods of DFC10PT10 and DFC1-PT10. Figure 4 plots the mean tree cover during the postdeforestation periods. In addition, because of the suppression of tree regrowth, PFT cover in the postdeforestation period of DFC10-PT10 actually continues to decrease at roughly $0.003 \mathrm{Mkm}^{2} \mathrm{yr}^{-1}$ for the evergreens and $0.005 \mathrm{Mkm}^{2} \mathrm{yr}^{-1}$ for the deciduous trees $\left(0.60 \%\right.$ and $0.43 \% \mathrm{yr}^{-1}$, respectively, relative to the start of the postdeforestation period). Similarly, the DFC1-PT10 tree cover also decreases, though at slower rates of approximately $0.001 \mathrm{Mkm}^{2} \mathrm{yr}^{-1}$ for the evergreens and $0.004 \mathrm{Mkm}^{2} \mathrm{yr}^{-1}$ for the deciduous trees (0.73\% and $0.83 \% \mathrm{yr}^{-1}$, respectively). In the control case, tropical trees are actually slightly increasing. The differences in the rates of tree-to-grass conversion is presented in Figure 5, which shows the change in foliar projective cover in the tropical band of tropical trees versus the grasses during the first 100 years of the simulation. 
Earth Interactions • Volume 16 (2012) • Paper No. 4 • Page 10
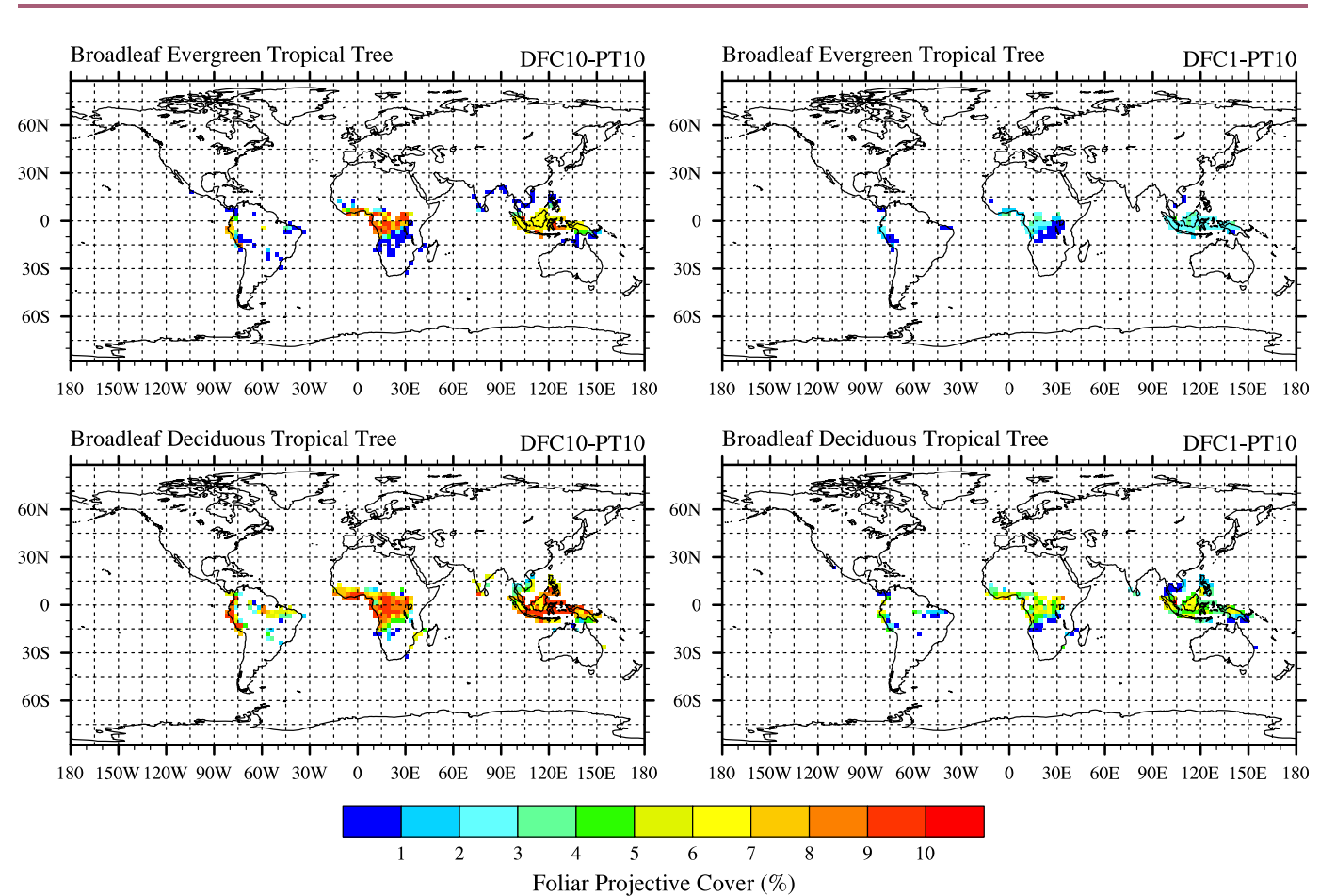

Figure 4. Tree cover for the (top) broadleaf evergreen tropical tree and (bottom) broadleaf deciduous tropical tree for the (left) DFC10-PT10 and (right) DFC1-PT10 cases averaged over their respective postdeforestation periods.

\subsection{Active deforestation period: Time dependence}

The deforestation rates produce characteristic trends in time for many of the biophysical variables considered (refer to Table 1 for a summary of trends over tropical land; also see supplemental material for plots at the Journals Online Web site: http://dx.doi.org/10.1175/EI390.s1). The $\Delta$ DFC10 case exhibits rapid changes in biophysical variables during the initial 10-30 years and then levels off, indicating that the preservation target is being reached and the vegetation distribution is stabilizing. By contrast, the $\triangle \mathrm{DFC} 1$ case exhibits more gradual changes throughout the first 50 years of deforestation.

In this model, albedo exhibits an immediate, first-order, and time-dependent response varying in accordance with the prescribed deforestation rates. Broadleaf evergreen and deciduous tropical trees (leaf albedo $=0.10$ and stem albedo $=0.16$ in the visible) both have a lower albedo than $\mathrm{C} 4$ grasses (leaf albedo $=0.11$ and stem albedo $=0.36$ in the visible), and hence deforestation causes significant albedo changes compared to the control. (For a complete list of reflectances, as well as other optical properties per PFT, refer to Oleson et al. 2004.) The change in all-sky albedo over tropical land for both deforestation cases is highly significant, increasing by an additional $0.069 \%$ of incoming radiation reflected per year for $\triangle \mathrm{DFC} 10$ (for the first 20 years of the branch run before vegetation cover stabilizes) 
Foliar Projective Cover

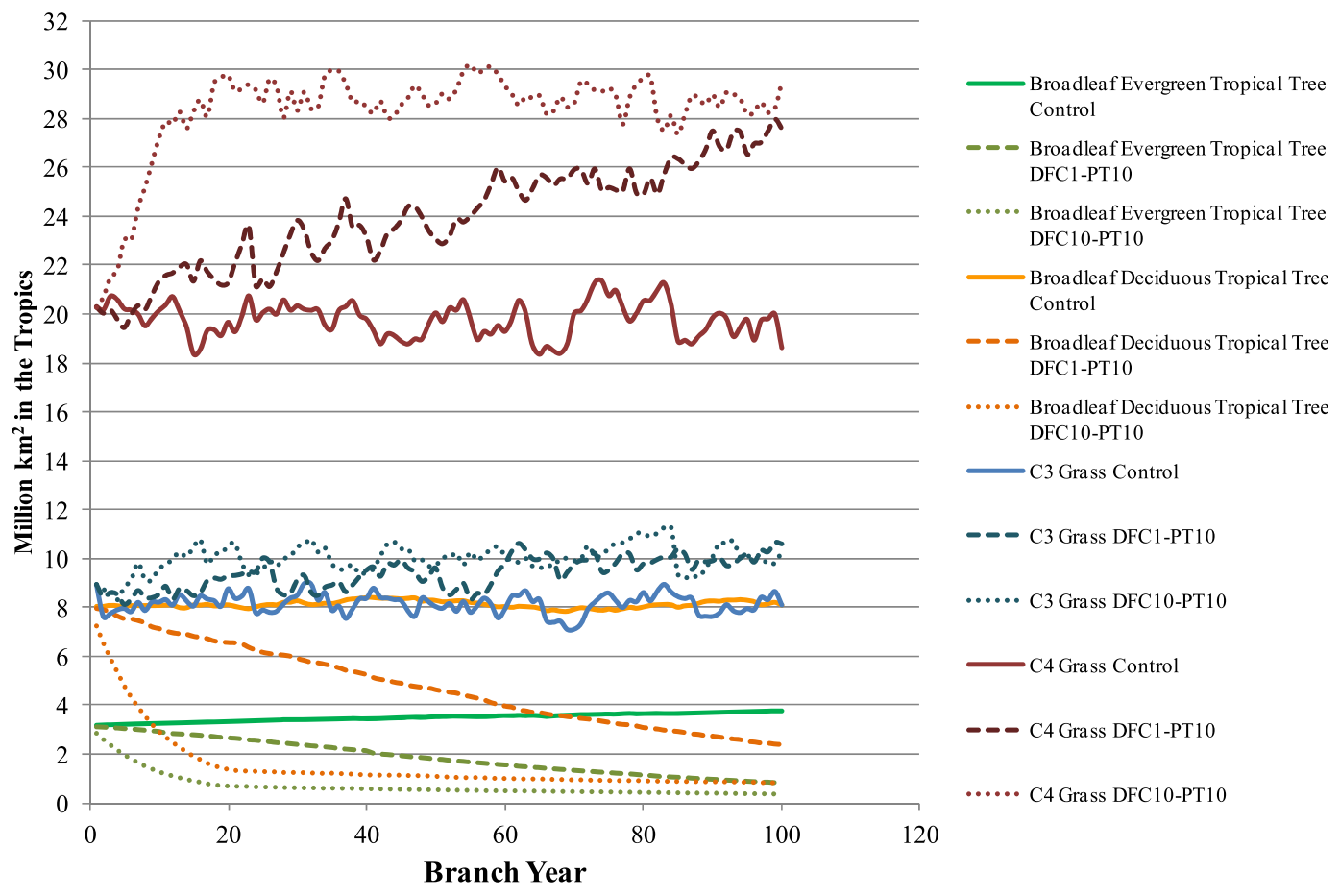

Figure 5. Total foliar projective cover in the tropical band $\left(30^{\circ} \mathrm{S}-30^{\circ} \mathrm{N}\right)$ of tropical tree types and grasses in the first 100 years of the control (solid lines), DFC 1-PT10 (dashed lines), and DFC10-PT10 (dotted lines) branches.

and $0.016 \%$ reflected per year for $\triangle \mathrm{DFC} 1$ (over the first 50 years of the branch run). The same is true for net radiation, which is decreasing at $-0.116 \mathrm{~W} \mathrm{~m}^{-2} \mathrm{yr}^{-1}$ over 20 years and $-0.033 \mathrm{~W} \mathrm{~m}^{-2} \mathrm{yr}^{-1}$ over 50 years for $\triangle \mathrm{DFC} 10$ and $\triangle \mathrm{DFC} 1$, respectively.

However, as expected, surface albedo and net radiation exhibit greater response to the deforestation rates over specific forested regions rather than over the entire tropical band. For example, in central Africa and Southeast Asia, the change in albedo is increasing at the rate of an additional $0.293 \%$ reflected per year and $0.273 \%$ reflected per year, respectively, over the first 20 years of $\triangle \mathrm{DFC} 10$ and $0.015 \%$ reflected per year and $0.056 \%$ reflected per year, respectively, over the first 50 years of $\triangle \mathrm{DFC} 1$. The change in net radiation is also greater regionally, at $-0.422 \mathrm{~W} \mathrm{~m}^{-2} \mathrm{yr}^{-1}$ over central Africa and $-0.429 \mathrm{~W} \mathrm{~m}^{-2} \mathrm{yr}^{-1}$ over Southeast Asia likewise during the first 20 years of $\triangle \mathrm{DFC} 10$ before vegetation cover stabilizes. For the $\triangle \mathrm{DFC} 1$ case, however, only Southeast Asia produces a significant decline at $-0.135 \mathrm{~W} \mathrm{~m}^{-2} \mathrm{yr}^{-1}$ over the first 50 years.

The trends in latent heat flux and its components through time also exhibit the respective "signatures" of the prescribed deforestation rates. Model results for latent heat flux in the $\triangle \mathrm{DFC} 10$ case exhibit a $-0.061 \mathrm{~W} \mathrm{~m}^{-2} \mathrm{yr}^{-1}$ rate of decline over the first 30 years before leveling off. In contrast, in the $\triangle \mathrm{DFC} 1$ simulation, the trend in latent heat flux is weak over the 50-yr regression period. Likewise, in 


\section{Earth Interactions - Volume 16 (2012) • Paper No. 4 • Page 12}

Table 1. Tropical land trends of biophysical and climate variables during the active deforestation period (branch years 1-50; simulation years 101-150). Annual changes in bold italics represent significant time dependence at a $95 \%$ level. Note that the time period over which the slope is calculated differs among the variables (refer to plots in S1).

\begin{tabular}{|c|c|c|c|c|c|c|}
\hline \multirow[b]{3}{*}{ Variables } & \multicolumn{6}{|c|}{ Tropical land trends } \\
\hline & \multicolumn{3}{|c|}{$\Delta \mathrm{DFC} 10$} & \multicolumn{3}{|c|}{$\Delta \mathrm{DFC} 1$} \\
\hline & $\begin{array}{c}\text { No. of } \\
\text { years for } \\
\text { trend analysis }\end{array}$ & Slope & $\begin{array}{l}\text { Pearson's } \\
\text { corr coef }\end{array}$ & $\begin{array}{c}\text { No. of } \\
\text { years for } \\
\text { trend analysis }\end{array}$ & Slope & $\begin{array}{l}\text { Pearson's } \\
\text { corr coef }\end{array}$ \\
\hline All-sky surface albedo $\left(\% \mathrm{yr}^{-1}\right)$ & 20 & 0.069 & 0.964 & 50 & 0.016 & 0.969 \\
\hline Net surface radiation $\left(\mathrm{W} \mathrm{m}{ }^{-2} \mathrm{yr}^{-1}\right)$ & 20 & -0.116 & -0.856 & 50 & -0.033 & -0.648 \\
\hline Latent heat flux ( $\left.\mathrm{W} \mathrm{m}^{-2} \mathrm{yr}^{-1}\right)$ & 30 & -0.061 & -0.517 & 50 & -0.014 & -0.267 \\
\hline Canopy transpiration $\left(\mathrm{W} \mathrm{m}^{-2} \mathrm{yr}^{-1}\right)$ & 20 & 0.075 & 0.851 & 50 & 0.002 & 0.108 \\
\hline Canopy evaporation $\left(\mathrm{W} \mathrm{m}^{-2} \mathrm{yr}^{-1}\right)$ & 10 & -0.317 & -0.836 & 50 & -0.029 & -0.532 \\
\hline Ground evaporation $\left(\mathrm{W} \mathrm{m}^{-2} \mathrm{yr}^{-1}\right)$ & 10 & 0.202 & 0.628 & 50 & 0.012 & 0.288 \\
\hline Ground temperature $\left(\mathrm{K} \mathrm{yr}^{-1}\right)$ & 50 & -0.003 & -0.244 & 50 & -0.001 & -0.074 \\
\hline Vegetation temperature $\left(\mathrm{K} \mathrm{yr}^{-1}\right)$ & 50 & -0.004 & -0.334 & 50 & -0.003 & -0.215 \\
\hline 2-m air temperature $\left(\mathrm{K} \mathrm{yr}^{-1}\right)$ & 50 & -0.004 & -0.350 & 50 & -0.003 & -0.237 \\
\hline Precipitation $\left(\mathrm{mm} \mathrm{yr}^{-1}\right)$ & 50 & -0.700 & -0.403 & 50 & -0.100 & -0.061 \\
\hline
\end{tabular}

$\triangle \mathrm{DFC} 10$, canopy (ground) evaporation also decreases (increases) sharply within the first decade but then reverses in trend as the grasses move in to replace the lost trees at the rate of $-0.317(0.202) \mathrm{W} \mathrm{m}^{-2} \mathrm{yr}^{-1}$. Model results for the $\Delta \mathrm{DFC} 1$ case also show a significant though weaker trend in canopy and ground evaporation at -0.029 and $0.012 \mathrm{~W} \mathrm{~m}^{-2} \mathrm{yr}^{-1}$ over the first 50 years.

The same trends are magnified in the regional forests. Canopy evaporation in the $\triangle \mathrm{DFC} 10$ case decreases rapidly at -1.434 and $-2.240 \mathrm{~W} \mathrm{~m}^{-2} \mathrm{yr}^{-1}$ in central Africa and Southeast Asia, respectively, in the first decade. Conversely, ground evaporation increases sharply in central Africa at $1.045 \mathrm{~W} \mathrm{~m}^{-2} \mathrm{yr}^{-1}$ and in Southeast Asia at $1.083 \mathrm{~W} \mathrm{~m}^{-2} \mathrm{yr}^{-1}$. In the $\triangle \mathrm{DFC} 1$ case, the decreasing (increasing) trend in canopy (ground) evaporation is gradual but sustained. Southeast Asia again exhibits the greater response with a decrease in canopy evaporation of $-0.362 \mathrm{~W} \mathrm{~m}^{-2} \mathrm{yr}^{-1}$ and an increase in ground evaporation of $0.191 \mathrm{~W} \mathrm{~m}^{-2} \mathrm{yr}^{-1}$ over the first 50 years of the branch case. In central Africa, the response is diminished with a decrease in canopy evaporation of $0.101 \mathrm{~W} \mathrm{~m}^{-2} \mathrm{yr}^{-1}$ and an increase in ground evaporation of $0.123 \mathrm{~W} \mathrm{~m}^{-2} \mathrm{yr}^{-1}$.

Canopy transpiration, however, presents an issue in both deforestation rate scenarios. Contrary to the expected initial decline in canopy transpiration as tree removal occurs, the trend in canopy transpiration is positive over tropical land. Caution must be exercised, however, in interpreting these results for moisture fluxes given hydrological parameterizations in the model that partition evapotranspiration such that it is dominated by ground and canopy evaporation, resulting in a low tree transpiration bias (Lawrence et al. 2007; Bonan and Levis 2006). However, with the decrease in canopy-intercepted precipitation in the deforestation scenarios, evaporation from wetted tree leaf and stem area also decreases, whereas transpiration from the dry, sunlit grass leaf area increases. However, transpiration is also connected to leaf area index (LAI), and global and regional LAI are found to decrease in both cases. 
In preliminary offline runs conducted with CLM3.5-DGVM (Oleson et al. 2007), which improves on the partitioning scheme of CLM3 (modifications and performance documented in Oleson et al. 2008), canopy transpiration behaves in accordance with theory, decreasing with deforestation (refer to the Journals Online Web site: http://dx.doi.org/10.1175/EI390.s2). Within only the first 10 years of the $\triangle \mathrm{DFC} 10$ case, transpiration decreases by approximately $11.0 \mathrm{~W} \mathrm{~m}^{-2}$ in the Amazon basin, $12.0 \mathrm{~W} \mathrm{~m}^{-2}$ in central Africa, and $14.9 \mathrm{~W} \mathrm{~m}^{-2}$ in Southeast Asia. In the $\triangle \mathrm{DFC} 1$ case, 50 years are required to reach a decrease of approximately $10.5 \mathrm{~W} \mathrm{~m}^{-2}$ in the Amazon basin, $11.0 \mathrm{~W} \mathrm{~m}^{-2}$ in central Africa, and $13.5 \mathrm{~W} \mathrm{~m}^{-2}$ in Southeast Asia. As a trade-off, the magnitude of the decrease in canopy evaporation is smaller compared to the results from CCSM3-DGVM.

In contrast to the clear and immediate biophysical signal caused by the timedependent deforestation, the climate feedback over tropical land is weaker. The typical signatures of $\triangle \mathrm{DFC} 10$ versus $\triangle \mathrm{DFC} 1$ through time are absent. Only in $\Delta \mathrm{DFC} 10$ after 50 years are significant changes detected in temperature and precipitation, although the magnitude of the change is small (on the order of a thousandth of a kelvin per year) and correlation coefficients are relatively low. Also, the temperatures are decreasing rather than increasing over tropical land, suggesting that the warm/dry bias may be weakening what we would expect to be a net warming effect from the reduced latent heat flux. In $\triangle \mathrm{DFC} 1$, none of the temperature and precipitation variables considered show significant trends within the 50-yr period.

Again, the model suggests that climate response is stronger when averaged over specific forested regions; differences in trend caused by the rates are more apparent. For example, ground temperatures in the $\triangle \mathrm{DFC} 1$ case increase at a gradual though significant rate of $0.009 \mathrm{~K} \mathrm{yr}^{-1}$ for central Africa and $0.016 \mathrm{~K} \mathrm{yr}^{-1}$ for Southeast Asia over 50 years. However, in the $\triangle \mathrm{DFC} 10$ case, they increase rapidly in the first 10 years at a rate of 0.157 and $0.108 \mathrm{~K} \mathrm{yr}^{-1}$ in central Africa and Southeast Asia, respectively. This means an increase of more than $1 \mathrm{~K}$ in both regions within the short span of a decade in this particular model. Furthermore, note that, because this is an average over the region, there are grid cells experiencing even faster temperature increases. Warmer ground temperatures will have implications on soil respiration and decomposition processes, the rate of ground evaporation, surface-air temperature gradients, and the exchange of energy and moisture. The magnitude of increase seen here is comparable to CCSM3's climate sensitivity to doubling $\mathrm{CO}_{2}$. CCSM3's transient response to $\mathrm{CO}_{2}$ doubling at the rate of $1 \% \mathrm{yr}^{-1}$ is $1.48 \mathrm{~K}$, whereas the equilibrium sensitivity is $2.47 \mathrm{~K}$ (Kiehl et al. 2006).

Similar results are obtained for regional annual precipitation. Precipitation in all regions exhibits weak sensitivity to the rate of deforestation, again likely influenced by the dry bias. The trend is a decreasing one, although the actual magnitude of the change is small (e.g., a decline in the Amazon basin at $-1.14 \mathrm{~mm} \mathrm{yr}^{-1}$, in central Africa at $-1.49 \mathrm{~mm} \mathrm{yr}^{-1}$, and in Southeast Asia at $-3.34 \mathrm{~mm} \mathrm{yr}^{-1}$ for $\triangle \mathrm{DFC} 10$ over 50 years) compared to the large interannual variability. Only Southeast Asia's trend is a statistically significant decline in the $\triangle \mathrm{DFC} 10$ case, and there are no significant trends in the $\triangle \mathrm{DFC} 1$ case. Still, for a rapid deforestation scenario in Southeast Asia, this implies a decrease of $167 \mathrm{~mm}$, which represents $5.43 \%$ of the initial annual $3073.5 \mathrm{~mm}$ in Southeast Asia after being spun up, over 


$$
\text { Earth Interactions - Volume } 16 \text { (2012) • Paper No. } 4 \text { • Page } 14
$$

Table 2. Slope (trend) and Pearson's correlation coefficients of biophysical and climate variables regressed against total tropical tree foliar projective cover, as averaged over tropical land, during the active deforestation period (branch years 1-50; simulation years 101-150). Slopes and coefficients in bold italics represent significant time dependence at a $95 \%$ level.

\begin{tabular}{lrrrrr}
\hline \multicolumn{1}{c}{ Tropical land } & \multicolumn{2}{c}{ DFC10-PT10 } & & \multicolumn{2}{c}{ DFC1-PT10 } \\
\cline { 2 - 3 } \cline { 5 - 6 } Variables & Slope & Pearson's corr coef & & Slope & Pearson's corr coef \\
\hline All-sky surface albedo $\left(\% \mathrm{Mkm}^{-2}\right)$ & $-\mathbf{0 . 1 6 5}$ & $-\mathbf{0 . 9 8 9}$ & & $-\mathbf{0 . 1 4 1}$ & $-\mathbf{0 . 9 7 9}$ \\
Net surface radiation $\left(\mathrm{W} \mathrm{m}^{-2} \mathrm{Mkm}^{-2}\right)$ & $\mathbf{0 . 2 7 4}$ & $\mathbf{0 . 8 7 0}$ & & $\mathbf{0 . 2 6 5}$ & $\mathbf{0 . 6 9 4}$ \\
Latent heat flux $\left(\mathrm{W} \mathrm{m}^{-2} \mathrm{Mkm}^{-2}\right)$ & $\mathbf{0 . 1 8 9}$ & $\mathbf{0 . 5 3 9}$ & & $\mathbf{0 . 1 5 8}$ & $\mathbf{0 . 3 7 8}$ \\
Canopy transpiration $\left(\mathrm{W} \mathrm{m}^{-2} \mathrm{Mkm}^{-2}\right)$ & $-\mathbf{0 . 1 5 2}$ & $-\mathbf{0 . 8 4 2}$ & & -0.014 & -0.078 \\
Canopy evaporation $\left(\mathrm{W} \mathrm{m}^{-2} \mathrm{Mkm}^{-2}\right)$ & $\mathbf{0 . 1 2 5}$ & $\mathbf{0 . 4 2 0}$ & & $\mathbf{0 . 4 5 0}$ & $\mathbf{0 . 7 8 7}$ \\
Ground evaporation $\left(\mathrm{W} \mathrm{m}^{-2} \mathrm{Mkm}^{-2}\right)$ & $\mathbf{0 . 2 1 6}$ & $\mathbf{0 . 5 0 6}$ & & $-\mathbf{0 . 2 7 9}$ & $-\mathbf{0 . 6 1 4}$ \\
Ground temperature $\left(\mathrm{K} \mathrm{Mkm}^{-2}\right)$ & -0.002 & -0.039 & & -0.021 & -0.176 \\
Vegetation temperature $\left(\mathrm{K} \mathrm{Mkm}^{-2}\right)$ & 0.016 & 0.239 & & 0.006 & 0.049 \\
2-m air temperature $\left(\mathrm{K} \mathrm{Mkm}^{-2}\right)$ & 0.015 & 0.246 & & 0.005 & 0.040 \\
Precipitation $\left(\mathrm{mm} \mathrm{Mkm} \mathrm{Mkm}^{-2}\right)$ & $\mathbf{3 . 7 6 0}$ & $\mathbf{0 . 3 9 4}$ & & 1.140 & 0.085 \\
\hline
\end{tabular}

only half a century. Historically, most of the region has been found to experience this magnitude of change over 1901-2005 (Trenberth et al. 2007).

\subsection{Active deforestation period: Sensitivity to tropical tree foliar cover}

In this section, biophysical and climate trends from both DFC10-PT10 and DFC1-PT10 are presented as a function of tropical tree foliar projective cover (expressed in millions of square kilometers) over the first 50 years, rather than as a function of time. The trends, again calculated over a fixed period of the first 50 years of active deforestation, are summarized in Table 2.

Over tropical land, the sensitivities of surface albedo and net radiation to tree cover in DFC10-PT10 and DFC1-PT10 are both highly significant but too close to each other to make any practical difference from a policy perspective (i.e., for albedo, $-0.165 \%$ reflected $\mathrm{Mkm}^{-2}$ in DFC10-PT10 versus $-0.141 \%$ reflected $\mathrm{Mkm}^{-2}$ in DFC1-PT10; for net radiation, $0.274 \mathrm{~W} \mathrm{~m}^{-2} \mathrm{Mkm}^{-2}$ in DFC10-PT10 versus $0.265 \mathrm{~W} \mathrm{~m}^{-2} \mathrm{Mkm}^{-2}$ in DFC1-PT10). These model results indicate that the foliar cover sensitivity over tropical land is weakly affected by the rate of treecover removal. The same is true for the overall tropical latent heat flux in CCSM3DGVM; the sensitivity is significant at $0.189 \mathrm{~W} \mathrm{~m}^{-2} \mathrm{Mkm}^{-2}$ in DFC10-PT10 and $0.158 \mathrm{~W} \mathrm{~m}^{-2} \mathrm{Mkm}^{-2}$ in DFC1-PT10 (note again that these may be underestimations because of the dry bias). The components of the latent heat flux, however, are inconsistent between the two cases. For example, ground evaporation exhibits opposing trends in DFC10-PT10 versus DFC1-PT10; in the latter, the relationship with tropical tree foliar cover is an inverse one but, in the former, it is a positive one. These results are likely reflective of the hydrological partitioning issues combined with the rapid spread of grasses in DFC10-PT10, which begin to compensate for the canopy evapotranspiration and dampen ground evaporation in the middle of the 50-yr period. The climate response over tropical land also varies weakly with tree 


$$
\text { Earth Interactions • Volume } 16 \text { (2012) • Paper No. } 4 \text { • Page } 15
$$

Table 3. Slope (trend) and Pearson's correlation coefficients of biophysical and climate variables regressed against total tropical tree foliar projective cover, as averaged over the Amazon basin, during the active deforestation period (branch years 1-50; simulation years 101-150). Slopes and coefficients in bold italics represent significant time dependence at a $95 \%$ level.

\begin{tabular}{|c|c|c|c|c|}
\hline \multirow{2}{*}{$\begin{array}{c}\text { Amazon basin } \\
\text { Variables }\end{array}$} & \multicolumn{2}{|c|}{ DFC10-PT10 } & \multicolumn{2}{|c|}{ DFC1-PT10 } \\
\hline & Slope & Pearson's corr coef & Slope & Pearson's corr coef \\
\hline All-sky surface albedo $\left(\% \mathrm{Mkm}^{-2}\right)$ & -3.321 & -0.978 & -2.127 & -0.773 \\
\hline Net surface radiation $\left(\mathrm{W} \mathrm{m}^{-2} \mathrm{Mkm}^{-2}\right.$ ) & 3.068 & 0.233 & 4.864 & 0.205 \\
\hline Latent heat flux ( $\mathrm{W} \mathrm{m}^{-2} \mathrm{Mkm}^{-2}$ ) & 3.626 & 0.117 & -0.055 & -0.001 \\
\hline Canopy transpiration $\left(\mathrm{W} \mathrm{m}^{-2} \mathrm{Mkm}^{-2}\right)$ & 0.102 & 0.012 & 12.263 & 0.555 \\
\hline Canopy evaporation $\left(\mathrm{W} \mathrm{m}{ }^{-2} \mathrm{Mkm}^{-2}\right.$ ) & 8.275 & 0.264 & 27.478 & 0.311 \\
\hline Ground evaporation $\left(\mathrm{W} \mathrm{m}{ }^{-2} \mathrm{Mkm}^{-2}\right.$ ) & -4.750 & -0.215 & -39.797 & -0.526 \\
\hline Ground temperature $\left(\mathrm{K} \mathrm{Mkm}^{-2}\right)$ & -0.544 & -0.147 & -1.315 & -0.157 \\
\hline Vegetation temperature $\left(\mathrm{K} \mathrm{Mkm}^{-2}\right)$ & 0.108 & 0.029 & 0.101 & 0.014 \\
\hline 2-m air temperature $\left(\mathrm{K} \mathrm{Mkm}^{-2}\right)$ & -0.079 & -0.025 & -0.795 & -0.115 \\
\hline Precipitation $\left(\mathrm{mm} \mathrm{Mkm}^{-2}\right)$ & 2.240 & 0.080 & -8.520 & -0.141 \\
\hline
\end{tabular}

cover. In DFC1-PT10, there is no significant correlation between ground, vegetation, 2-m temperature or precipitation, and tropical tree foliar cover. In DFC10-PT10, only annual precipitation is significantly correlated at $3.760 \mathrm{~mm} \mathrm{Mkm}^{-2}$.

Regional correlations (summarized in Tables 3-5) reflect a stronger response of selected biophysical and climate variables to changes in foliar projective cover; however, model output suggests that sensitivities vary by region as well as by deforestation rate. For all regions, the sensitivities of albedo are highly significant and are larger in the DFC10-PT10 case compared to the DFC1-PT10 case, but central Africa has the highest sensitivity in either scenario, followed by the Amazon basin and Southeast Asia. Central Africa is also the only region with significant trends in net radiation, and, in this case, the difference between the two simulations' sensitivities may again be negligible from a practical point of view

Table 4. Slope (trend) and Pearson's correlation coefficients of biophysical and climate variables regressed against total tropical tree foliar projective cover, as averaged over central Africa, during the active deforestation period (branch years 1-50; simulation years 101-150). Slopes and coefficients in bold italics represent significant time dependence at a $95 \%$ level.

\begin{tabular}{|c|c|c|c|c|}
\hline \multirow{2}{*}{$\begin{array}{c}\text { Central Africa } \\
\text { Variables }\end{array}$} & \multicolumn{2}{|c|}{ DFC10-PT10 } & \multicolumn{2}{|c|}{ DFC1-PT10 } \\
\hline & Slope & Pearson's corr coef & Slope & Pearson's corr coef \\
\hline All-sky surface albedo $\left(\% \mathrm{Mkm}^{-2}\right)$ & -3.645 & -0.992 & -2.522 & -0.937 \\
\hline Net surface radiation $\left(\mathrm{W} \mathrm{m}{ }^{-2} \mathrm{Mkm}^{-2}\right.$ ) & 5.525 & 0.854 & 5.465 & 0.555 \\
\hline Latent heat flux $\left(\mathrm{W} \mathrm{m}^{-2} \mathrm{Mkm}^{-2}\right)$ & 2.918 & 0.653 & -0.850 & -0.072 \\
\hline Canopy transpiration $\left(\mathrm{W} \mathrm{m}^{-2} \mathrm{Mkm}^{-2}\right)$ & -4.464 & -0.929 & -0.684 & -0.156 \\
\hline Canopy evaporation $\left(\mathrm{W} \mathrm{m}{ }^{-2} \mathrm{Mkm}^{-2}\right.$ ) & 0.727 & 0.100 & 8.946 & 0.485 \\
\hline Ground evaporation ( $\mathrm{W} \mathrm{m}{ }^{-2} \mathrm{Mkm}^{-2}$ ) & 6.654 & 0.633 & -9.113 & -0.663 \\
\hline Ground temperature $\left(\mathrm{K} \mathrm{Mkm}^{-2}\right)$ & -0.573 & -0.707 & -0.821 & -0.494 \\
\hline Vegetation temperature $\left(\mathrm{K} \mathrm{Mkm}^{-2}\right)$ & 0.112 & 0.207 & 0.162 & 0.129 \\
\hline 2-m air temperature $\left(\mathrm{K} \mathrm{Mkm}^{-2}\right)$ & 0.120 & 0.239 & 0.003 & 0.002 \\
\hline Precipitation $\left(\mathrm{mm} \mathrm{Mkm}{ }^{-2}\right.$ ) & 1.930 & 0.439 & -2.090 & -0.145 \\
\hline
\end{tabular}




$$
\text { Earth Interactions • Volume } 16 \text { (2012) • Paper No. } 4 \text { • Page } 16
$$

Table 5. Slope (trend) and Pearson's correlation coefficients of biophysical and climate variables regressed against total tropical tree foliar projective cover, as averaged over Southeast Asian land, during the active deforestation period (branch years 1-50; simulation years 101-150). Slopes and coefficients in bold italics represent significant time dependence at a $95 \%$ level.

\begin{tabular}{lrrrrr}
\hline \multicolumn{1}{c}{ Southeast Asia } & \multicolumn{2}{c}{ DFC10-PT10 } & & \multicolumn{2}{c}{ DFC1-PT10 } \\
\cline { 2 - 3 } \cline { 5 - 6 } Variables & Slope & Pearson's corr coef & & Slope & Pearson's corr coef \\
\hline All-sky surface albedo $\left(\% \mathrm{Mkm}^{-2}\right)$ & $-\mathbf{0 . 6 9 1}$ & $-\mathbf{0 . 9 7 7}$ & & $-\mathbf{0 . 3 6 3}$ & $-\mathbf{0 . 7 0 6}$ \\
Net surface radiation $\left(\mathrm{W} \mathrm{m}^{-2} \mathrm{Mkm}^{-2}\right)$ & 0.611 & 0.223 & & 0.837 & 0.189 \\
Latent heat flux $\left(\mathrm{W} \mathrm{m}^{-2} \mathrm{Mkm}^{-2}\right)$ & 0.769 & 0.119 & & -0.363 & -0.026 \\
Canopy transpiration $\left(\mathrm{W} \mathrm{m}^{-2} \mathrm{Mkm}^{-2}\right)$ & -0.011 & -0.007 & & $\mathbf{2 . 4 2 5}$ & $\mathbf{0 . 5 8 8}$ \\
Canopy evaporation $\left(\mathrm{W} \mathrm{m}^{-2} \mathrm{Mkm}^{-2}\right)$ & 1.676 & 0.257 & & $\mathbf{4 . 7 1 4}$ & $\mathbf{0 . 2 8 5}$ \\
Ground evaporation $\left(\mathrm{W} \mathrm{m}^{-2} \mathrm{Mkm}^{-2}\right)$ & -0.896 & -0.194 & & $-\mathbf{7 . 5 0 2}$ & $-\mathbf{0 . 5 3 1}$ \\
Ground temperature $\left(\mathrm{K} \mathrm{Mkm}^{-2}\right)$ & -0.105 & -0.136 & & -0.221 & -0.142 \\
Vegetation temperature $\left(\mathrm{K} \mathrm{Mkm}^{-2}\right)$ & 0.034 & 0.045 & & 0.041 & 0.031 \\
2-m air temperature $\left(\mathrm{K} \mathrm{Mkm}^{-2}\right)$ & -0.005 & -0.008 & & -0.127 & -0.098 \\
Precipitation $\left(\mathrm{mm} \mathrm{Mkm} \mathrm{Mkm}^{-2}\right)$ & 0.540 & 0.093 & & -1.670 & -0.148 \\
\hline
\end{tabular}

(5.525 $\mathrm{W} \mathrm{m}^{-2} \mathrm{Mkm}^{-2}$ in DFC10-PT10 compared to $5.465 \mathrm{~W} \mathrm{~m}^{-2} \mathrm{Mkm}^{-2}$ in DFC1-PT10).

Model results show that latent heat flux, transpiration, and evaporations patterns are also inconsistent across the regions. Both the Amazon basin and Southeast Asia have no significant trends in latent heat flux or any of its components in the DFC10PT10 case but do have significant trends in transpiration and evaporation in DFC1PT10. Only central Africa has a significant trend in latent heat flux at $2.918 \mathrm{~W} \mathrm{~m}^{-2}$ $\mathrm{Mkm}^{-2}$ in DFC10-PT10. The strongest correlations between canopy evapotranspiration and ground evaporation are found in the Amazon basin, although the signs of trends of canopy transpiration and ground evaporation differ not only across regions but also between cases. Again, this is an instance in which the warm/dry bias comes into play and, if the output from CLM3.5-DGVM (see supplemental material at the Journals Online Web site: http://dx.doi.org/10.1175/EI390.s2) is any indication, we should expect more consistency in signs of trends among regions when this bias has been addressed. However, there will still likely be regional variations in the magnitude of these trends, as the results from CCSM3-DGVM suggest. In addition, this analysis of model output indicates that the period considered for the analysis influences the perceived sensitivities because grasses begin to influence model results midway through the 50 years in the DFC10-PT10 case.

The regression coefficients for climate variables are again mostly insignificant even at the regional level, except for ground temperature and precipitation in central Africa. The calculated increase in ground temperature that occurs with steady tree loss is smaller in DFC10-PT10 with a slope of $-0.573 \mathrm{~K} \mathrm{Mkm}^{-2}$ compared to $-0.821 \mathrm{~K} \mathrm{Mkm}^{-2}$ in DFC1-PT10, but note that the correlation coefficient is weaker in DFC1-PT10.

\subsection{Comments on the postdeforestation period}

In comparing the impacts of the rates, another important question is whether a "rapid but short" deforestation makes any difference from a "gradual but 
Earth Interactions - Volume 16 (2012) • Paper No. 4 • Page 17

prolonged" deforestation in terms of the long-term postdeforestation climate. In this case, however, the substantial differences in postdeforestation tree cover (due to the differing lengths of time of tree mortality and suppression of establishment) between DFC10-PT10 and DFC1-PT10 make a comparison of truly equivalent postdeforestation periods difficult. The former appears to be warmer overall over tropical land but only by a fraction; that is, ground, vegetation, and 2-m air temperatures are 298.21, 296.68, and 296.36 K compared to 297.98, 296.56, and $296.24 \mathrm{~K}$, respectively, in the DFC1-PT10 case. However, this is likely a manifestation of the lower albedo rather than of any systemic changes that the rate of tree loss may have caused. Surface albedo and net radiation over tropical land in DFC1-PT10 are $20.14 \%$ and $106.93 \mathrm{~W} \mathrm{~m}^{-2}$ compared to $20.01 \%$ and $107.25 \mathrm{~W} \mathrm{~m}^{-2}$ in DFC10-PT10.

The comparison of biophysical and climate variables of the DFC10-PT10 and DFC1-PT10 postdeforestation cases is given in more detail for interested readers (see supplemental material at the Journals Online Web site: http://dx.doi.org/ 10.1175/EI390.s3). However, caution must be taken in the interpretation given the caveat described here.

\section{Discussion}

The simulations performed here illustrate the preservation pathways described by Gurney and Raymond (Gurney and Raymond 2008) and are relevant to adaptation and mitigation initiatives. Forced annual tropical deforestation in the CCSM3-DGVM model triggers immediate radiative feedbacks and changes in heat and moisture fluxes. The incremental aspect of the deforestation produces rate-dependent signatures in time that are a potentially useful guideline for planning and project implementation. In the rapid deforestation case, DFC10PT10, the significant changes occur within the first three decades of active deforestation. In the gradual deforestation case, DFC1-PT10, the rate of change of biophysical variables is likewise slower but sustained because a time span on the order of centuries is required for all forested grid cells in the tropics to reach the preservation target. Thus, as shown in this model, the annual rates of deforestation can affect the temporal dynamics of terrestrial biophysical impacts in a crucial way. Adaptation and mitigation must be informed by the time dependence of feedbacks to be effective.

Not surprisingly, this model suggests that the biophysical impacts of tree-cover loss are stronger (by an order of magnitude), specifically in the regions where the deforestation actually occurs rather than over the entire tropical band. The net climatic impact under the deforestation scenarios employed show local warming of surface (ground/vegetation) and near-surface $(2 \mathrm{~m})$ air temperatures, largely because of changes in the surface energy budget and moisture fluxes. These temperature increases not only agree with previous simulations (e.g., Davin and de Noblet-Ducoudré 2009; Snyder et al. 2004; Claussen et al. 2001) but on a localized scale can attain magnitudes comparable to temperature changes due to doubled atmospheric $\mathrm{CO}_{2}$ (based on CCSM3's climate sensitivity). This is true of both deforestation cases simulated here. Changes in precipitation are likewise significant only on the local scale; however, it is likely that the warm/dry bias in the Amazon basin-a region believed to influence precipitation on a global scale 
(Werth and Avissar 2002) — acts so as to dampen the response over the Amazon basin as well as the larger-scale trends.

The results underscore the importance of initial conditions in addition to the deforestation rates. The initial tree populations spun up by the model influence if and how biophysical and climate variables evolve in time. In the case of the Amazon basin, for example, because the tree foliar cover is severely underestimated, there is minimal deforestation before the preservation target and reached. Hence, the trends in time are not as notable as those in central Africa and Southeast Asia. Thus, the analysis of preservation pathways is supplemented here by determining correlations with remaining tropical tree foliar cover. In this case, when the radiative properties, latent heat flux, and climate variables are averaged over the entire tropical band, there is no apparent sensitivity to the deforestation rate; that is, the correlation to foliar projective cover is similar in both DFC10-PT10 and DFC1-PT10. This implies some linearity in Earth system response at this scale, contrary to the hypothesis that the rapid deforestation case represents a larger annual perturbation and might therefore provoke a greater response per year as well as per unit area. Only the canopy evapotranspiration and ground evaporation show variation between the two cases, but no conclusions can be drawn here in light of CCSM3's issues with the partitioning of the latent heat flux.

When examined at a regional level over the fixed time period, the sensitivity to tropical tree foliar projective cover varies across both regions and rates, particularly for latent heat flux, transpiration, and evaporation. The climate response as well, having a less direct connection to land cover compared to the surface biophysical variables, still exhibits a weaker correlation to the loss of tropical tree cover. However, this is likely again influenced by the hydrological deficiencies in CCSM3, as well as the length of the period of analysis (in the DFC10-PT10 case, the moisture fluxes are affected not only by the dwindling tree cover but also by the rapidly spreading grass cover beginning midway through the 50 years considered). Because of the warm/dry bias and the lack of forest cover in the Amazon basin, it is difficult to draw any definitive conclusions with regards to the actual value of the sensitivities of each region as well as relative magnitudes of the sensitivities among the regions. Thus, the point to underscore here is that there exists the possibility of significant differences in regional sensitivities to deforestation rates. This further implies that regional peculiarities (i.e., location, geography, and climate) influence the response to the forcing. However, whether the sensitivity to change is also a function of the rate of that change (i.e., the deforestation rate) has yet to be proven robust.

Comparing DFC10-PT10 and DFC1-PT10 over the long term, we find that the imposition of the preservation target does not guarantee that different pathways will lead to the same vegetation cover (and hence the same biophysical-climate impacts), particularly with the suppression of tree establishment. The deforestation rate and initial conditions determine when each grid cell reaches the preservation target and hence the overall vegetation distribution over a large area at any point in time. The model suggests that, with rapid deforestation, forest grid cells more likely arrive at the target at nearly the same time. With gradual deforestation, decades separate when different grid cells reach the target.

The simulations by this particular model produce a postdeforestation DFC10PT10 case that has slightly more vegetation cover (by about 1\%-3\% based on 
Earth Interactions - Volume 16 (2012) • Paper No. 4 • Page 19

Figure 4). However, this should not be misconstrued as being an argument for rapid rather than gradual deforestation. The fact still remains that, in the DFC10-PT10 case, forests are depleted in a matter of only a few decades, whereas the DFC1PT10 case requires over a century. A rapid rate of deforestation would compromise the integrity of other ecosystem services as well as the ability to sustain biodiversity. In addition, if the former simulation were to be continued as long as the latter, the tree cover would be in a worse state.

This model also omits key carbon feedbacks that will likely be affected by the rate of deforestation. For example, the carbon flux to the atmosphere will cause a warming but may also trigger a slight carbon fertilization effect in the remaining tree population. The slower the rate of tree removal, the longer trees are able to sequester carbon and provide a cooling feedback. However, depending on whether a substantial preservation target is imposed, this additional carbon storage may only be returned to the atmosphere at a later time. It is hypothesized that the net effect of complete biophysical and biogeochemical feedbacks would be that of more rapid and significant warming, both regionally and globally, which, if confirmed, will pose a challenge to adaptation and mitigation efforts.

The next step, then, is a more comprehensive and rigorous characterization of the nature of the Earth system response to varying deforestation rates at different spatial scales and the determination of factors that influence sensitivities in time in to tree cover. Given the serious hydrological biases in CCSM3, model simulations of hydroclimate must be improved or other Earth system models must be used to prove tropical and regional sensitivities robust.

Future research should then incorporate the following: 1) more simulations, possibly with different models, with full integration of biophysics and biogeochemistry (including the impact of land-atmosphere carbon fluxes on atmospheric $\mathrm{CO}_{2}$ concentrations) to determine the net climate impact and to what extent biophysical feedbacks will influence biogeochemical feedbacks; 2) an ensemble approach to better separate noise from signal, particularly in order to look at (i) lower deforestation rates; (ii) interannual climate variability, transient shocks, and climate extremes while deforestation forcing is applied; (iii) regional/local impacts; and (iv) teleconnections; and 3) the integration of human decision making regarding land use to select grid cells prognostically in accordance with socioeconomic and climate feedback optimization rather than to have the forcing prescribed in the model code.

\section{Conclusions}

This study describes a straightforward approach for incorporating time-dependent, transient deforestation into the CCSM framework while maintaining interactive vegetation, biophysics, and climate. It describes how biophysics and climate vary in time in rapid (DFC10-PT10) versus gradual (DFC1-PT10) deforestation and explores methods for measuring and comparing regional sensitivities to tropical tree cover. Although specific conclusions cannot be made with certainty about the actual values of these trends and sensitivities because of the warm/dry bias of CCSM3DGVM, this study nevertheless shows that it is feasible to simulate deforestation rates and to detect these sensitivities using current Earth system models (while underscoring the importance taking into account biases that might affect temporal 
Earth Interactions - Volume 16 (2012) • Paper No. 4 • Page 20

and spatial dynamics). The model simulations lend strength to the hypothesis that the rate of deforestation, a parameter rarely considered in deforestation simulations, can influence the rate of climatic changes through biophysical mechanisms at the local or regional scale.

These results may have significant implications on land-climate policy. From a policy point of view, the timing of tropical deforestation impacts on climate may prove to be crucial. Though the long-term impacts that manifest over centuries may be beyond the planning horizon, the immediate trends in key Earth system parameters and the immediacy of significant temperature shifts are most relevant for crafting short- to medium-term adaptation and mitigation actions and development plans. Going back to the Gurney and Raymond (Gurney and Raymond 2008) "preservation pathways," the rate of tree cover loss may represent an additional consideration aside from the target amount of preserved forest cover. This applies to REDD planning and implementation as well.

This study, however, does not make an argument for either "rapid but short" or "gradual but prolonged" deforestation policies because of the absence of key feedback mechanisms (i.e., from the Amazon rain forest and via carbon pathways) and existence of other forest services not discussed here (e.g., water, biodiversity, livelihoods). It only demonstrates that the transient impacts as well as the long-term climatologies will potentially differ significantly depending on the rate. Whether there are nonlinearities in the Earth system response to the differences in yearly perturbations has yet to be determined. This initial study therefore contends that the question of deforestation rates is one worth further analysis.

This line of research will contribute to advancing our understanding of landatmosphere dynamics and key biophysical-climate feedbacks. A more complete understanding of feedbacks will, in turn, assist in improving Earth system models and in generating more realistic and comprehensive climate change scenarios. It can also clarify the discussion on defining more appropriate climate metrics for the value of slowing deforestation: one that can, on the one hand, encompass the full range of feedbacks and reflect the magnitude and direction of those feedbacks but, on the other hand, is not too cumbersome for policy purposes. This study can help shape the policy response in order to maximize "climate effectiveness" of mitigation and adaptation initiatives at both the regional and global levels. In this sense, the question of deforestation rates is relevant not only to climate science but also to development planning.

Acknowledgments. CCSM3 was provided by the National Center for Atmospheric Research (NCAR). NCAR is sponsored by the National Science Foundation (NSF). For the fully coupled simulations, this research used resources of the Oak Ridge Leadership Computing Facility, located in the National Center for Computational Sciences at Oak Ridge National Laboratory, which is supported by the Office of Science of the Department of Energy under Contract DE-AC05-00OR22725. Computing time was provided through the Climate-Science Computational End Station Development-University Collaborations project of the INCITE program. For the offline CLM3 spinup, computational resources were provided by Information Technology at Purdue, Rosen Center for Advanced Computing, West Lafayette, Indiana. Funding support for the authors was provided by the Purdue Climate Change Research Center (PCCRC), the Schlumberger Faculty for the 
Earth Interactions - Volume 16 (2012) • Paper No. 4 • Page 21

Future Fellowship, and the Fulbright program. Many thanks also to Matt Huber (Purdue University) for his assistance in running CCSM3, Sam Levis (NCAR) for his assistance in running CLM-DGVM and his comments on this paper, and the anonymous reviewers for their suggestions.

\section{References}

Avissar, R., and D. Werth, 2005: Global hydroclimatological teleconnections resulting from tropical deforestation. J. Hydrometeor., 6, 134-145.

Bala, G., K. Caldeira, M. Wickett, T. J. Phillips, D. B. Lobell, C. Delire, and A. Mirin, 2007: Combined climate and carbon-cycle effects of large-scale deforestation. Proc. Natl. Acad. Sci. USA, 104, 6550-6555.

Barker, T., and Coauthors, 2007: Technical summary. Climate Change 2007: Mitigation. B. Metz et al., Eds., Cambridge University Press, 19-92.

Betts, R. A., 2000: Offset of the potential carbon sink from boreal forestation by decreases in surface albedo. Nature, 408, 187-190.

Bonan, G. B., 2008: Forests and climate change: Forcings, feedbacks and the climate benefit of forests. Science, 320, 1444-1449.

_- and S. Levis, 2006: Evaluating aspects of the Community Land and Atmosphere Models (CLM3 and CAM3) using a dynamic global vegetation model. J. Climate, 19, 22902301.

— D. Pollard, and S. L. Thompson, 1992: Effects of boreal forest vegetation on global climate. Nature, 359, 716-718.

Brovkin, V., A. Ganopolski, M. Claussen, C. Kubatzki, and V. Petoukhov, 1999: Modelling climate response to historical land cover change. Global Ecol. Biogeogr., 8, 509-517.

Canadell, J. G., and M. R. Raupach, 2008: Managing forests for climate change mitigation. Science, 320, 1456-1457.

Chapin, F. S., III, J. T. Randerson, A. D. McGuire, J. A. Foley, and C. B. Field, 2008: Changing feedbacks in the climate-biosphere system. Front. Ecol. Environ., 6, 313-320.

Claussen, M., V. Brovkin, and A. Ganopolski, 2001: Biogeophysical versus biogeochemical feedbacks of large-scale land cover change. Geophys. Res. Lett., 28, 1011-1014.

Collins, W. D., M. L. Blackmon, G. B. Bonan, J. J. Hack, T. B. Henderson, J. T. Kiehl, W. G. Large, and D. S. McKenna, 2006: The Community Climate System Model version 3 (CCSM3). J. Climate, 19, 2122-2143.

Davin, E., and N. de Noblet-Ducoudré, 2009: Climatic impact of global-scale deforestation: Radiative versus nonradiative version. J. Climate, 23, 97-112.

FAO, cited 2010: Global forest resources assessment 2010. Food and Agriculture Organization. [Available online at http://www.fao.org/forestry/fra/fra2010/en/.]

Feddema, J. J., K. W. Oleson, G. B. Bonan, L. O. Mearns, L. E. Buja, G. A. Meehl, and W. M. Washington, 2005: The importance of land-cover change in simulating future climates. Science, 310, 1674-1678.

Findell, K. L., T. R. Knutson, and P. C. D. Milly, 2006: Weak simulated extratropical responses to complete tropical deforestation. J. Climate, 19, 2835-2850.

Gibbard, S., K. Caldeira, G. Bala, T. J. Phillips, and M. Wickett, 2005: Climate effects of global land cover change. Geophys. Res. Lett., 32, L23705, doi:10.1029/2005GL024550.

Govindasamy, B., P. B. Duffy, and K. Caldeira, 2001: Land use changes and Northern Hemisphere cooling. Geophys. Res. Lett., 28, 291-294.

Gumpenberger, M., K. Vohland, U. Heyder, B. Poulter, K. Macy, A. Rammig, A. Popp, and W. Cramer, 2010: Predicting pan-tropical climate change induced forest stock gains and losses-Implications for REDD. Environ. Res. Lett., 5, 014013, doi:10.1088/1748-9326/5/1/ 014013. 


\section{Earth Interactions - Volume 16 (2012) • Paper No. 4 • Page 22}

Gurney, K. R., and L. Raymond, 2008: Targeting deforestation rates in climate change policy: A "preservation pathway" approach. Carbon Balance Manage., 3, doi:10.1186/1750-0680-3-2.

Hassan, R., R. Scholes, and N. Ash, Eds., 2005: Current States and Trends. Vol. 1, Ecosystems and Human Well-Being, Island Press, 948 pp.

Henderson-Sellers, A., R. E. Dickinson, T. B. Durbidge, P. J. Kennedy, K. McGuffie, and A. J. Pitman, 1993: Tropical deforestation: Modeling local- to regional-scale climate change. J. Geophys. Res., 98, 7289-7315.

Jackson, R. B., and Coauthors, 2008: Protecting climate with forests. Environ. Res. Lett., 3, 044006, doi:10.1088/1748-9326/3/4/044006.

Kiehl, J. T., C. A. Shields, J. J. Hack, and W. D. Collins, 2006: The climate sensitivity of the Community Climate System Model version 3 (CCSM3). J. Climate, 19, 2584-2596.

Lawrence, D. M., P. E. Thornton, K. W. Oleson, and G. B. Bonan, 2007: The partitioning of evapotranspiration into transpiration, soil evaporation, and canopy evaporation in a GCM: Impacts on land-atmosphere interaction. J. Hydrometeor, 8, 862-880.

Lawrence, P. J., and T. N. Chase, 2010: Investigating the climate impacts of global land cover change in the Community Climate System Model. Int. J. Climatol., 30, 2066-2087.

Levis, S., M. Vertenstein, and K. W. Oleson, 2004: The Community Land Model's Dynamic Global Vegetation Model (CLM-DGVM): Technical description and user's guide. National Center for Atmospheric Research Tech. Note TN-459+IA, 50 pp.

Marland, G., and Coauthors, 2003: The climatic impacts of land surface change and carbon management, and the implications for climate-change mitigation policy. Climate Policy, 3, 149-157.

Nabuurs, G. J., and Coauthors, 2007: Forestry. Climate Change 2007: Mitigation. B. Metz et al., Eds., Cambridge University Press, 541-584.

Nepstad, D. C., C. M. Stickler, B. Soares-Filho, and F. Merry, 2008: Interactions among Amazon land use, forests and climate: Prospects for a near-term forest tipping point. Phil. Trans. Roy. Soc., 363B, 1737-1746.

Oleson, K. W., and Coauthors, 2004: Technical description of the Community Land Model (CLM). National Center for Atmospheric Research Tech. Note TN-461+STR, 174 pp.

—_, and Coauthors, 2007: CLM3.5 documentation. UCAR Rep., 35 pp. [Available online at http:// www.cgd.ucar.edu/tss/clm/distribution/clm3.5/CLM3_5_documentation.pdf.]

— - and Coauthors, 2008: Improvements to the Community Land Model and their impact on the hydrological cycle. J. Geophys. Res., 113, G01021, doi:10.1029/2007JG000563.

Pielke, R. A., Sr., G. Marland, R. A. Betts, T. N. Chase, J. L. Eastman, J. O. Niles, D. D. S. Niyogi, and S. W. Running, 2002: The influence of land-use change and landscape dynamics on the climate system: Relevance to climate-change policy beyond the radiative effect of greenhouse gases. Philos. Trans. Roy. Soc. London, 360A, 1705-1719.

Poulter, B., and Coauthors, 2010: Net biome production of the Amazon basin in the 21st century. Global Change Biol., 16, 2062-2075.

Robledo, C. and J. Blaser, 2008: Key issues on land use, land use change and forestry (LULUCF) with an emphasis on developing country perspectives. United Nations Development Programme Environment \& Energy Group Publication, 26 pp. [Available online at http:// www.undp.org/climatechange/docs/English/UNDP_LULUCF_final.pdf.]

Schaeffer, M., B. Eickhout, M. Hoogwijk, B. Strengers, D. van Vuuren, R. Leemans, and T. Opsteegh, 2006: $\mathrm{CO}_{2}$ and albedo climate impacts of extratropical carbon and biomass plantations. Global Biogeochem. Cycles, 20, GB2020, doi:10.1029/2005GB002581.

Schurgers, G., U. Mikolajewicz, M. Gröger, E. Maier-Reímer, M. Vizcaíno, and A. Winguth, 2008: Long-term effects of biogeophysical and biogeochemical interactions between terrestrial biosphere and climate under anthropogenic climate change. Global Planet. Change, 64, 26-37.

Sitch, S., and Coauthors, 2003: Evaluation of ecosystem dynamics, plant geography and terrestrial carbon cycling in the LPJ dynamic global vegetation model. Global Change Biol., 9, $161-185$. 


\section{Earth Interactions • Volume 16 (2012) • Paper No. 4 • Page 23}

- V. Brovkin, W. von Bloh, D. van Vuuren, B. Eickhout, and A. Ganopolski, 2005: Impacts of future land use cover changes on atmospheric $\mathrm{CO}_{2}$ and climate. Global Biogeochem. Cycles, 19, GB2013, doi:10.1029/2004GB002311.

Snyder, P. K., J. A. Foley, M. H. Hitchman, and C. Delire, 2004: Effects of tropical forest removal on the regional climate using a detailed three-dimensional energy budget: An application to Africa. J. Geophys. Res., 109, D21102, doi:10.1029/2003JD004462.

Trenberth, K. E., and Coauthors, 2007: Observations: Surface and atmospheric climate change. Climate Change 2007: The Physical Science Basis, S. Solomon et al., Eds., Cambridge University Press, 235-336.

Van der Werf, G. R., D. C. Morton, R. S. DeFries, J. G. G. Olivier, P. S. Kasibhatla, R. B. Jackson, G. J. Collatz, and J. T. Randerson, 2009: $\mathrm{CO}_{2}$ emissions from forest loss. Nat. Geosci., 2, 737 738.

Werth, D., and R. Avissar, 2002: The local and global effects of Amazon deforestation. J. Geophys. Res., 107, 8087, doi:10.1029/2001JD000717.

Zhang, H., A. Henderson-Sellers, and K. McGuffie, 2001: The compounding effects of tropical deforestation and greenhouse warming on climate. Climatic Change, 49, 309-338.

Earth Interactions is published jointly by the American Meteorological Society, the American Geophysical Union, and the Association of American Geographers. Permission to use figures, tables, and brief excerpts from this journal in scientific and educational works is hereby granted provided that the source is acknowledged. Any use of material in this journal that is determined to be "fair use" under Section 107 or that satisfies the conditions specified in Section 108 of the U.S. Copyright Law (17 USC, as revised by P.IL. 94553) does not require the publishers' permission. For permission for any other from of copying, contact one of the copublishing societies. 